\title{
The Transition and Crystal Transformation of Poly[3,3-bis(chloromethyl)oxacyclobutane] under High Pressure
}

\author{
Kazumi Matsushige, Susumu Hirakawa, ${ }^{*}$ \\ and Tetuo TAKemura \\ Department of Applied Science, Faculty of Engineering, \\ Kyushu University, Fukuoka, Japan. \\ (Received May 31, 1971)
}

\begin{abstract}
The effect of pressure on melting, crystal transformation, and glass transition of poly[3,3-bis(chloromethyl)oxacyclobutane], Penton, has been studied up to $7000 \mathrm{~kg} / \mathrm{cm}^{2}$ by the DTA and dilatometric method.

The melting temperature-pressure curve for the sample crystallized under high pressure indicates a maximum at about $2800 \mathrm{~kg} / \mathrm{cm}^{2}$, although that for the sample crystallized at atmospheric pressure shows a steady increase with pressure. The sample crystallized under pressure above the maximum point shows a diffused X-ray pattern, the broad melting peak in DTA scan and the positive volume change upon melting in dilatometric measurement. Under pressure above $1800 \mathrm{~kg} / \mathrm{cm}^{2}$, Penton crystallizes in the $\beta$-form, not in the $\alpha$-form. Further it is observed that the $\beta$-form transforms to the $\alpha$-form by means of annealing at the pressure range of $1800-2000 \mathrm{~kg} / \mathrm{cm}^{2}$.

The pressure dependence of glass transition temperature of Penton is comparatively small, $10-13^{\circ} \mathrm{C} / 1000 \mathrm{~kg} / \mathrm{cm}^{2}$. After cooling the sample from rubbery state to glassy state under pressure and reducing suddenly the applied pressure, the subsequent volumetemperature curve shows an anomalous increase around the glass transition temperature, which should be measured at the reduced pressure.

KEY WORDS Penton / High Pressure / Melting Temperature Maximum / Crystal Transformation / DTA / Dilatometric Method / Glass Transition / Densified Glass /
\end{abstract}

In high polymers, remarkable effects of pressure appear under a relatively low-pressure region, so that many investigations on high polymers under pressure have been undertaken and various phenomena which can not be seen at atmospheric pressure have been reported. For example, the formation of the extended-chain structure of polyethylene ${ }^{1}$ at $5000 \mathrm{~kg} / \mathrm{cm}^{2}$ and the crystal modification which are stable under high pressure, such as the $\gamma$-form of isotactic polypropylene ${ }^{2}$ and the phase III of poly(vinylidene fluoride), ${ }^{3}$ and the existence and nature of highpressure phase in poly(tetrafluoroethylene) ${ }^{4}$ have been reported.

On poly[3,3-bis(chloromethyl)oxacyclobutane], $-\left(-\mathrm{CH}_{2} \mathrm{C}\left(\mathrm{CH}_{2} \mathrm{Cl}\right)_{2}-\mathrm{CH}_{2} \mathrm{O}_{-}\right){ }_{n}$, hereafter referred

\footnotetext{
* Department of Applied Physics, Faculty of Science, Fukuoka University, Fukuoka, Japan.
}

to as Penton, it has previously been shown to exist in two crystal forms. ${ }^{5}$ The $\alpha$-form is obtained when Penton is cooled slowly from the molten state, and the crystallization from the quenched glassy state yields the $\beta$-form. On the effects of the pressure on Penton, Kardos has reported that Penton crystallizes in the $\beta$ form at $5000 \mathrm{~kg} / \mathrm{cm}^{2}$. Further, Baer and Kardos have obtained a melting temperature-pressure curve up to $3000 \mathrm{~kg} / \mathrm{cm}^{2}$ by the piston displacement method. The obtained curve shows that the pressure dependence of melting temperature becomes smaller with increasing pressure, so if the measurements of melting temperature are carried out in a higher pressure region (above $3000 \mathrm{~kg} / \mathrm{cm}^{2}$ ), it is expected that the melting temperature maximum will occur in this polymer as in the case of elements. ${ }^{8}$ Concerning the 
reason for the occurence of the melting temperature maximum in elements, various ideas have been proposed. Kennedy, et al. ${ }^{9}$ have suggested that the specific volume of solid becomes larger than that of the liquid above the pressure corresponding to the maximum melting point. Rapport ${ }^{10}$ has proposed a model that two kinds of phases which have different density exist in the liquid state, and Yoshida and Okamoto ${ }^{11}$ have proved theoretically the existence of a maximum in melting curve on the assumption that the crystal has properly soft repulsion interatomic potential. But there is a question whether this melting temperature maximum phenomenon is definitely explainable by these simple theories and models. It is supposed, as discussed by Weir ${ }^{12}$ that the structure of material becomes very complex and the melting phenomenon is not so simple under high pressure. Also it should be noted, according to the thermodynamic Clausius-Clapeyron equation $\left(\mathrm{d} T_{\mathrm{m}} / \mathrm{d} P=\Delta V / \Delta S\right)$, the volume change upon melting $(\Delta V)$ should be negative above the pressure of the maximum point. But this negative volume change has never been observed experimentally, and it is not clear whether the ClausiusClapeyron equation is available, since the complicated phase change may occur under high pressure. So it is valid to study in detail the phenomenon of melting temperature maximum on the polymer, which has a more complicated structure. In this study Penton was examined as the polymer material, and the occurence of melting temperature maximum in Penton is reported.

As to the nature of glass transition under high pressure, some studies have been carried out. For example, O'Reilly ${ }^{13}$ has measured the glass transition temperature under the pressure of poly(vinyl acetate), and $\mathrm{Gee}^{14}$ has analyzed thermodynamically the effect of pressure on the glass transition temperature of polystyrene. Investigations regarding the degree of equilibrium and stability of the densified glasses, which are produced by the vitrification under high pressure, have been performed by Shishkin ${ }^{15}$ for poly(methyl methacrylate) and other substances, and by Saito ${ }^{16}$ for poly(vinyl chloride). But for the densified glasses, dilatometric study under high pressure and the investigation of the pressure hysteresis phenomenon have not been carried out yet, and there is no report on the glass transition of Penton under pressure.

The objects of this investigation are to obtain the melting temperature-pressure curve up to the higher-pressure region and to study the crystal structure of Penton crystallized under high pressure. Further, the pressure dependence of the glass transition temperature and the pressure hysteresis phenomenon in the glass transition region are studied.

\section{EXPERIMENTAL}

\section{Apparatus}

An intensifier and pressure vessel system was used in this study. For the measurement of the thermal expansion a compound cylinder-type high-pressure vessel was used. The inner and the outer cylinders were made of DBC steel at $R_{\mathrm{c}}=48$. The vessel had an inner diameter $30 \mathrm{~mm} \phi$ and an outer diameter $120 \mathrm{~mm} \phi, K_{1} / K_{2}=1$ and $K_{1} K_{2}=4$, where $K_{1}$ and $K_{2}$ are the ratios of the outer and inner diameters of the inner and outer cylinders, respectively. This vessel could be used up to the pressure $14000 \mathrm{~kg} / \mathrm{cm}^{2}$. For the differential thermal analysis (DTA) a simple cylinder-type high-pressure DTA cell was used. This DTA cell had an inner diameter $10 \mathrm{~mm} \phi$ and an outer diameter $50 \mathrm{~mm} \phi$. The pressure measurement was done with the Bourdon pressure gauge in the lower-pressure side of the intensifier and the pressure calibration was made by the observation of the well defined solid-state transition of poly(tetrafluoroethylene). ${ }^{4}$

The thermal expansion measurement apparatus, shown in Figure 1, was inserted into the compound cylinder-type high-pressure vessel and six electrodes of differential transformer, two electric leads of inner sheathed heater ( $1.5 \mathrm{~mm} \phi$, Philips) and one sheathed chromel-alumel thermocouple ( $1 \mathrm{~mm} \phi$, Philips) were taken out from the pressure vessel using the previous technique. ${ }^{17}$ The excellent characteristics of the differential transformer in dilatometric measurements under high pressure has been shown in a previous paper. ${ }^{4}$ In this study a modified apparatus for measurement under high temperature (inner heater) and measurement of thermal expansion of liquid (piston cylinder type) was used. For the sake of accu- 


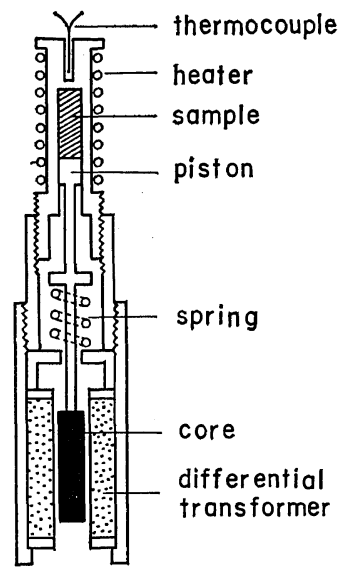

Figure 1. The apparatus for the thermal expansion measurement under high pressure.

rate measurement of the glass transition temperature at atmospheric pressure, apparatus after Vanderman's method ${ }^{18}$ was used.

In the case of DTA, a pair of sheathed chromel-alumel thermocouples, which were set in parallel within the high-pressure DTA cell, were used for temperature measurements of the specimen and reference [poly(tetrafluoroethylene)]. Each end of the thermocouples was inserted into the center of the specimen and reference material. The temperature was raised or lowered at a constant rate by the sheathed heater wound round this DTA cell. The thermal symmetry of this DTA apparatus was excellent.

The schematic diagrams of the apparatus for the DTA and thermal expansion measurement under high pressure are shown in Figure 2.

As the pressure medium, silicon oil was used for most cases. But in the experiment of dilatometric measurement under higher pressure (above about $5000 \mathrm{~kg} / \mathrm{cm}^{2}$ ), kerosene was used as the pressure medium, since the differential transformer bobbin made of porcelain is destroyed by the effect of the pressure strain caused by the poor fluidity of silicon oil under higher pressure.

Debye-Scherrer diffraction patterns were obtained by using $\mathrm{Cu}-\mathrm{K} \alpha$ radiation.

\section{Materials and Procedure}

Penton 9215 (lot number 12187) supplied by the Hercules Powder Company was used as the sample in this investigation.

The DTA, dilatometric measurement and Xray analysis were performed by the following procedures. Procedure 1: After samples were crystallized under pressure, the DTA and dilatometric measurement were performed under the same pressure as the crystallization pressure. Procedure 2: After samples were crystallized at atmospheric pressure, the DTA was performed under pressure. Procedure 3: After samples were crystallized under pressure, the DTA and X-ray analysis were performed at atmospheric pressure. Procedures 1 and 2 were adopted for the study of pressure dependence of melting temperature in Penton. Procedure 3 was adopted for the study of complicated behavior in crystal structure

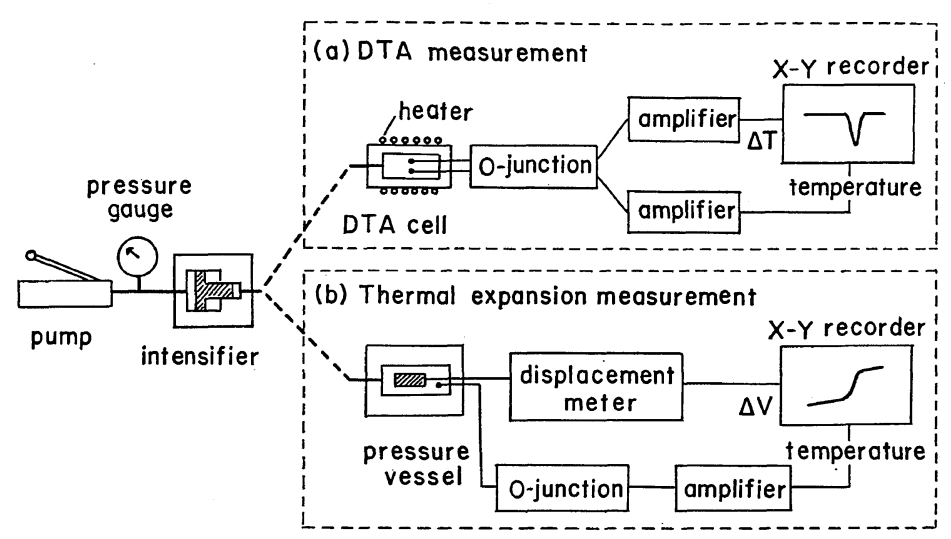

Figure 2. Schematic diagram of the apparatus for the DTA and the thermal expansion measurement under high pressure: (a), for the DTA; (b), for the thermal expansion measurement. 
of Penton crystallized under high pressure. The crystallization of samples under high pressure and atmospheric pressure were carried out by the following procedure. After annealing the sample for about $10 \mathrm{~min}$ at $10-20^{\circ} \mathrm{C}$ above the melting temperature at each desired pressure, the sample was cooled to room temperature under the same pressure at cooling rate of about $10^{\circ} \mathrm{C} / \mathrm{min}$ for the DTA and about $2^{\circ} \mathrm{C} / \mathrm{min}$ for the dilatometric measurement and X-ray analysis. In all DTA and dilatometric measurements the heating rates were about $10^{\circ} \mathrm{C} / \mathrm{min}$ and $2{ }^{\circ} \mathrm{C} / \mathrm{min}$, respectively.

In the case of measurement of the glass transition temperature, the temperature was raised fully above the glass transition point, up to the vicinity of melting temperature of Penton, and then the sample was cooled at the rate of about $2{ }^{\circ} \mathrm{C} /$ min under the constant pressure. After this procedure the volume change was measured at slow heating rate of about $1.5^{\circ} \mathrm{C} / \mathrm{min}$. The procedure in the case of study of the pressure hysteresis in the glass transition range is described later.

\section{RESULTS AND DISCUSSION}

\section{Melting and Crystal Transformation}

Pressure Dependence of Melting Temperature. Figure 3 shows the results of DTA by Procedure 1 . The lowest temperature peak is the endothermic one of the solid-state transition of poly(tetrafluoroethylene) as the reference material, therefore this endothermic peak appears just like the exothermic one on the DTA curve in this figure. Below about $3500 \mathrm{~kg} / \mathrm{cm}^{2}$ two endothermic peaks of fusion of Penton can be seen, but the lowertemperature peak indicated by arrow is very small and becomes indistinguishable above 3500 $\mathrm{kg} / \mathrm{cm}^{2}$. The main peak and sub peak indicated by the arrow are due to the fusion of the $\beta$ form and paracrystalline part in Penton, respectively, as discussed later.

Figure 4 shows the melting temperaturepressure curves of Penton by DTA melting signals. The curve (1) is the melting temperature-pressure curve obtained by Procedure 2 and shows the steady increase with pressure. On the other hand, the DTA scan obtained by Procedure 1 has two endothermic peaks, and

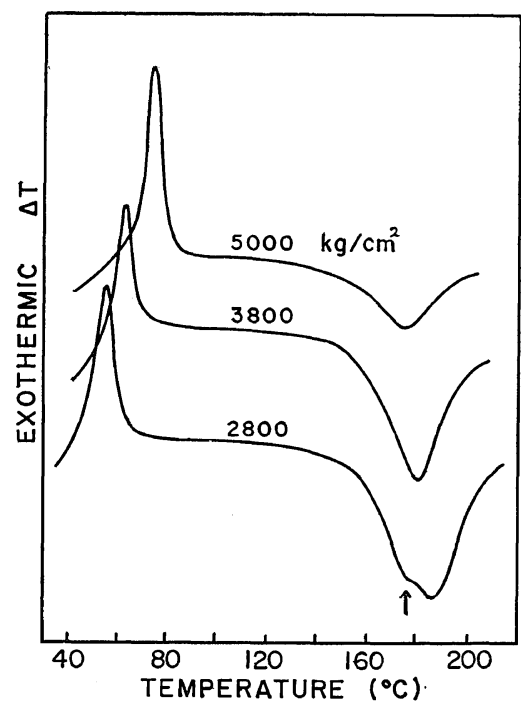

Figure 3. The DTA curves under each pressure. The higher temperature endothermic peak is due to the fusion of Penton. The lowest temperature peak is due to the solid state transition of poly(tetrafluoroethylene) as the reference material.

the curves (2) and (3) show the pressure dependence of these two peak points. Below about $1800 \mathrm{~kg} / \mathrm{cm}^{2}$ there is little difference between the melting curves (1) and (2), and these two curves overlap one another in that pressure region. Above that pressure, however, the melting curve (2) branches off from the curve (1) and indicates a maximum at about $2800 \mathrm{~kg} / \mathrm{cm}^{2}$. For this pressure dependence of melting temperature indicated by this curve (2), whether the ClausiusClapeyron equation $\left(\mathrm{d} T_{\mathrm{m}} / \mathrm{d} P=\Delta V / \Delta S\right)$ is available or not was examined subsequently by the measurement of volume change upon melting for the sample crystallized under pressure. If this melting phenomenon is simple, the volume change upon melting $(\Delta V)$ should become negative above $2800 \mathrm{~kg} / \mathrm{cm}^{2}$. Figure 5 shows the volume-temperature curves at $1000 \mathrm{~kg} / \mathrm{cm}^{2}, 2700$ $\mathrm{kg} / \mathrm{cm}^{2}$, and $4300 \mathrm{~kg} / \mathrm{cm}^{2}$. Dotted lines indicate the volume change on the cooling process and there is little contraction of sample volume in the stage of crystallization under higher pressure. In these experiments of thermal expansion under pressure, two peaks observed in the DTA melting signal are inseparable and the melting point can not be determined exactly. The melting tem- 


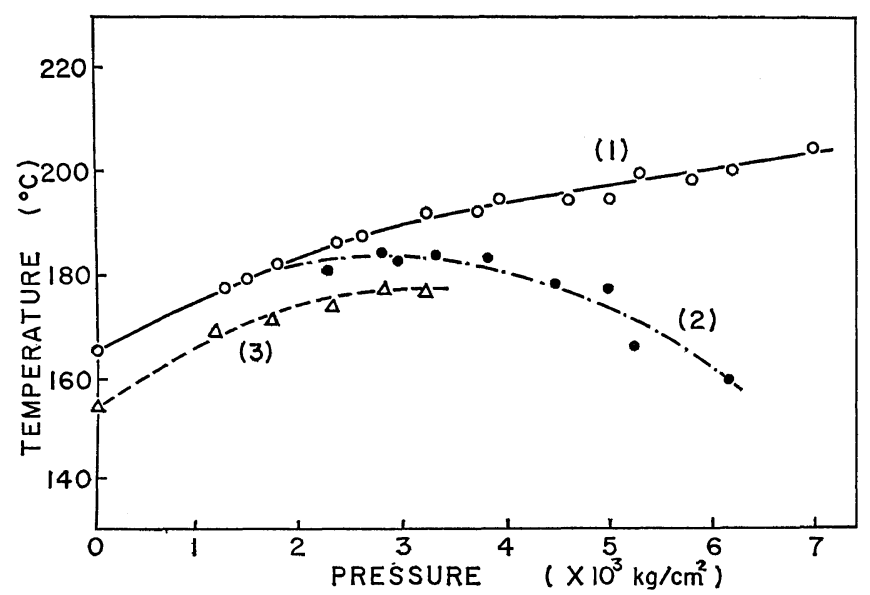

Figure 4. Pressure dependence of the melting temperature in Penton. The curve (1) represents the melting temperature-pressure curve for samples crystallized at atmospheric pressure (Procedure 2). Curves (2) and (3) represent the ones for samples crystallized under the same pressure as the measurement pressure (Procedure 1).

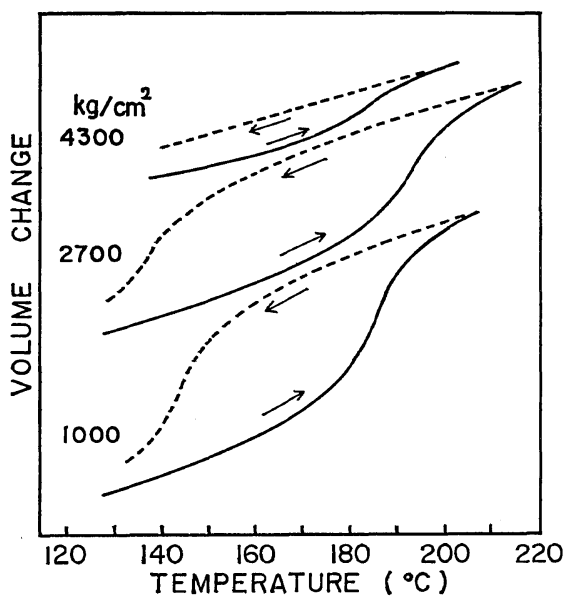

Figure 5. Volume-temperature curves under each pressure. The samples were crystallized under each pressure (Procedure 1). Dotted lines indicate the volume change in the cooling process.

perature-pressure curve from the volume change measurement has a maximum point as that from the DTA, as shown in Figure 6. The dotted line in Figure 6 indicates the pressure dependence of the crystallization temperature. The melting temperature and the crystallization temperature are determined by the inflection points in the obtained volume-temperature curves. The difference between the melting temperature in the

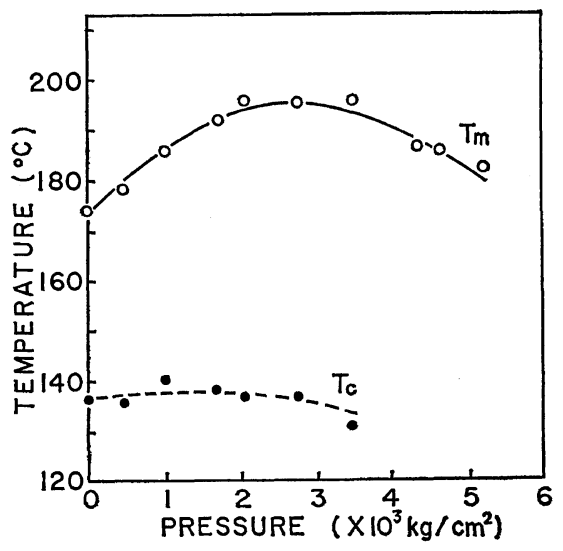

Figure 6. The pressure dependence of the melting temperature $\left(T_{\mathrm{m}}\right)$ and the crystallization temperature $\left(T_{\mathrm{c}}\right)$. The sample for the melting temperature measurement is the one crystallized under each pressure (Procedure 1). These data are obtained from the dilatometric measurements.

DTA and the one in the dilatometric measurement may result from the experimental conditions, such as heating and cooling rates, and from the difference of determination methods in the each measurement.

As shown in Figure 5, the volume change in the stage of melting under pressure above 2800 $\mathrm{kg} / \mathrm{cm}^{2}$ is still positive. Therefore this fact sug- 
gests that for the sample of Penton crystallized under pressure the Clausius-Clapeyron equation is not available in this melting phenomenon under higher pressure, and that any change of the crystal phase or structure may occur by the difference of crystallization conditions. For the explanation of this phenomenon in the pressure dependence of melting temperature, it is necessary to investigate in detail the structure of Penton crystallized under pressure.

Structure of Samples Crystallized under High Pressure. To study about the crystal structure of Penton crystallized under high pressure, the DTA and X-ray analysis at atmospheric pressure were performed (Procedure 3).

In Figure 7 the curve (2) (crystallized at atmospheric pressure) and the curve (3) (crystallized at $1000 \mathrm{~kg} / \mathrm{cm}^{2}$ ) have the endothermic peak of the $\alpha$-form at about $168^{\circ} \mathrm{C}$. The X-ray diffraction patterns demonstrate that these samples crystallized in the $\alpha$-form, as shown in Figure 9. But the endothermic peaks of curve (4) (crystallized at $\left.2000 \mathrm{~kg} / \mathrm{cm}^{2}\right)$, curve (5) (at $\left.4200 \mathrm{~kg} / \mathrm{cm}^{2}\right)$, curve (6) $\left(\right.$ at $6000 \mathrm{~kg} / \mathrm{cm}^{2}$ ), and curve (1) (quenched at

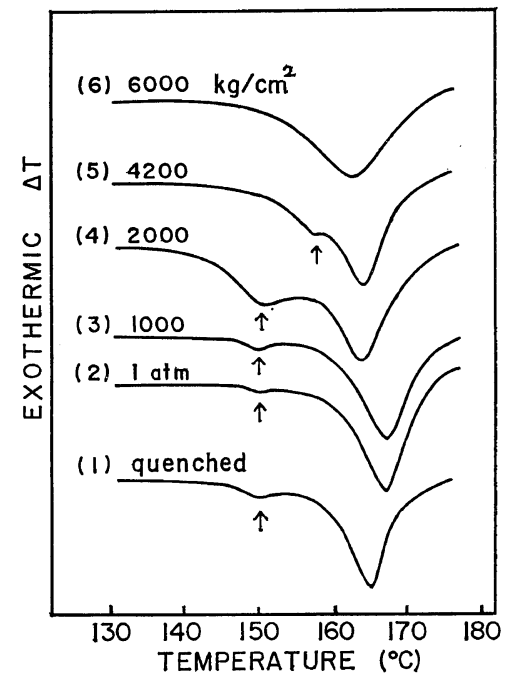

Figure 7. The DTA curves for the samples crystallized under the following crystallization pressure: (1) $6000 \mathrm{~kg} / \mathrm{cm}^{2}$, (2) $4200 \mathrm{~kg} / \mathrm{cm}^{2}$, (3) $2000 \mathrm{~kg} / \mathrm{cm}^{2}$, (4) $1000 \mathrm{~kg} / \mathrm{cm}^{2}$, and (5) atmospheric pressure. The curve (6) is obtained from the sample quenched from the molten state to the temperature of liquid $\mathrm{N}_{2}$. These DTA studies were carried out at atmospheric pressure (Procedure 3).
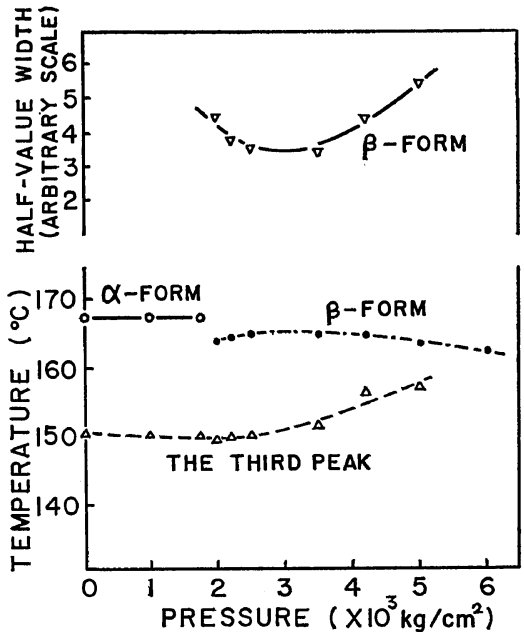

Figure 8. The peak temperature and the halfvalue width of the DTA melting peaks in Figure 7 as a function of the crystallization pressure.

atmospheric pressure) shows the fusion of the $\beta$-form at about $163-166^{\circ} \mathrm{C}$. These X-ray diffraction patterns demonstrate that these samples crystallized in the $\beta$-form, as shown in Figure 9.

The peak temperature and the half-value width of peaks in these DTA curves are plotted as a function of the crystallization pressure in Figure 8. The melting temperature of the $\beta$-form of sample crystallized under pressure has a maximum at about $2800 \mathrm{~kg} / \mathrm{cm}^{2}$, corresponding to the melting temperature-pressure curve (2) in Figure 4. The half-value width of the $\beta$-form has a minimum value about the crystallization pressure corresponding to the melting temperature maximum. The diffused X-ray diffraction patterns from samples crystallized under higher pressure $\left(4200 \mathrm{~kg} / \mathrm{cm}^{2}\right.$ and $\left.6000 \mathrm{~kg} / \mathrm{cm}^{2}\right)$, as shown in Figure 9, have a good correspondence to the increase of the half-value width and the lowering of melting temperature of the $\beta$-form in Figure 8. The reason for the diffuseness in the $\mathrm{X}$-ray pattern seems to be due to the existence of disordered parts in the crystal structure of paracrystalline parts and the low crystallinity. These imperfections in the structure of the $\beta$-form in the sample crystallized under higher pressure may form one of the factors for the lowering of the melting temperature under higher pressure.

The third endothermic peaks indicated by arrows in Figure 7 have a tendency to approach 


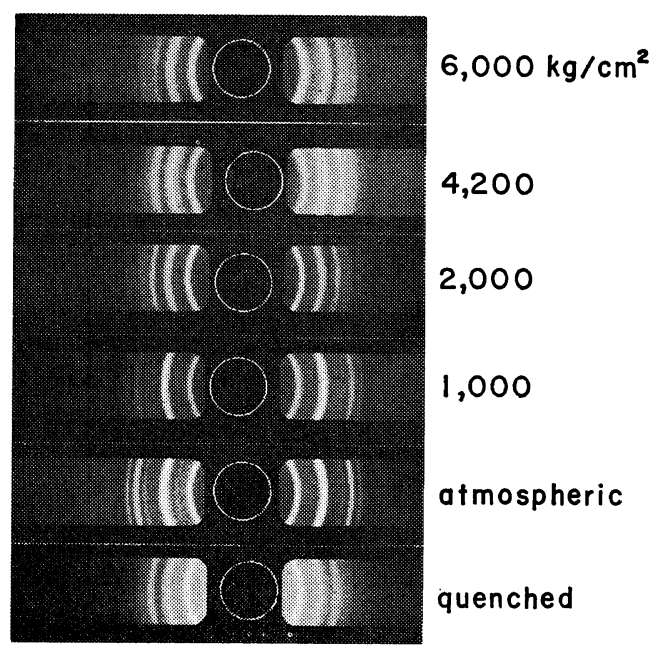

Figure 9. The X-ray powder photographs of Penton. Samples were obtained under the conditions described in Figure 7.

to the peaks of the $\beta$-form with increasing pressure as shown in Figure 8. This third peak corresponds to the sub peak in Figure 3. For the origin of this third peak, there are the following two differing speculations; the one is the $\beta$ to $\alpha$-form transformation ${ }^{19}$ and the other is the fusion of paracrystalline parts. ${ }^{20}$ But our following observations support the latter speculation, that the third peak is due to the fusion of paracrystalline parts. When the sample was heated up to the temperature below this third peak point and then the sample was cooled back to the room temperature, the subsequent DTA scan showed that the third peak grew up. And further, the DTA scan for the sample which had been heated once up to the temperature above the third peak point, but below the $\beta$ form peak, showed the only $\beta$-form peak. On the other hand, the sample which has a clear third peak in DTA curve shows the diffuse Xray diffraction pattern. These facts suggest that the disappearence of this third peak does not mean the $\beta$ to $\alpha$-form transformation and the origin of this third peak may be due to fusion of the paracrystalline-like parts.

Concerning the $\beta$ to $\alpha$-form transformation the following experiments were performed under high pressure.

Transformation of the $\beta$ to $\alpha$-Form under High Pressure. At atmospheric pressure it is reported that the $\beta$-form transforms to the $\alpha$-form by annealing at the temperature above about $140^{\circ} \mathrm{C}^{19,20}$

In order to examine the stability of the $\beta$ form under pressure and to study the time effect of the $\beta$ to $\alpha$-form transformation under high pressure, the samples were annealed for various time at crystallization temperature on the cooling process from the molten state. The determination of the crystal forms of these samples was made by observations of the DTA scan and the X-ray diffraction pattern at atmospheric pressure. If the samples were cooled at the rate of about $8^{\circ} \mathrm{C} / \mathrm{min}$ to room temperature without annealing at the crystallization temperature, the DTA curves from samples crystallized under pressure below $1750 \mathrm{~kg} / \mathrm{cm}^{2}$ indicated the $\alpha$-form peak and the ones from samples crystallized under pressure above about $1800 \mathrm{~kg} / \mathrm{cm}^{2}$ indicated the $\beta$-form, as described before.

When samples were annealed at each crystallization temperature for longer than 5 and $100 \mathrm{~min}$ at $1800 \mathrm{~kg} / \mathrm{cm}^{2}$ and $2000 \mathrm{~kg} / \mathrm{cm}^{2}$, respectively, the DTA scans showed that the $\beta$-form transformed to the $\alpha$-form during the process of the crystallization under pressure. On the contrary the DTA scans from samples annealed for $13 \mathrm{hr}$ at $2250 \mathrm{~kg} / \mathrm{cm}^{2}$ and for $45 \mathrm{hr}$ at $2500 \mathrm{~kg} / \mathrm{cm}^{2}$ showed still the $\beta$-form peak. Similar results were obtained by the $\mathrm{X}$-ray diffraction pattern. These observations suggest that the $\beta$-form is unstable and transforms to the $\alpha$-form during the annealing process for a fairly short time in the pressure range of $1800-2000 \mathrm{~kg} / \mathrm{cm}^{2}$, but under higher pressure the $\beta$-form is stable and does not transform easily to the $\alpha$-form.

Why Penton crystallizes in the $\beta$-form and the $\beta$-form does not transform to the $\alpha$-form under higher pressure, the following origins are suspected. First, the unit cell of the $\beta$-form has the larger axis ratio $\left(b / a=0.90^{21}\right)$ than that of the $\alpha$-form $\left(b / a=0.46^{21}\right)$, so that Penton may crystallize in the $\beta$-form, which has more isotropic crystal structure, from the molten state under pressure. Second, although the density of the $\beta$-form is a little lower than that of the $\alpha$-form ${ }^{21,22}$ at atmospheric pressure, the $\beta$-form may become a denser structure than the $\alpha$-form under higher pressure by its larger compressibility. Third, Penton has a high-potential barrier of 
rotation about the main chain due to the largeside chain $\left(\mathrm{CH}_{2} \mathrm{Cl}\right)$ located on opposite sides of the zigzag plane. ${ }^{21,22}$ Therefore, with increasing pressure, its barrier may become higher and the relaxation time of the $\beta$ to $\alpha$-form transformation may become much longer. But these speculations have not yet been verified experimentally.

\section{Pressure Effect on Glass Transition Temperature}

Pressure Dependence of Glass Transition Temperature. The glass transition temperature $\left(T_{\mathrm{g}}\right)$ of Penton at atmospheric pressure was measured by using the apparatus after Vanderman. ${ }^{18}$ From the obtained volume-temperature curve, $T_{\mathrm{g}}$ was determined to be $3^{\circ} \mathrm{C}$, although Sanzharovskii, et al., have reported that $T_{\mathrm{g}}$ is $-10^{\circ} \mathrm{C} .^{23}$

The $T_{\mathrm{g}}$ under high pressure was detected by the thermal expansion apparatus shown in Figure 1. Figure 10 shows the monotonous pressure dependence of $T_{\mathrm{g}}$ in Penton. In the pressure range of $1-3000 \mathrm{~kg} / \mathrm{cm}^{2}, \mathrm{~d} T_{\mathrm{g}} / \mathrm{d} P$ is about $13^{\circ} \mathrm{C} / 1000$ $\mathrm{kgcm}^{-2}$ and in the higher pressure range of $3000-5000 \mathrm{~kg} / \mathrm{cm}^{2}$, it is about $10^{\circ} \mathrm{C} / 1000 \mathrm{kgcm}^{-2}$. Compared with the values of other polymers, such as $\mathrm{d} T_{\mathrm{g}} / \mathrm{d} P=22$ [poly(vinyl acetate)], ${ }^{13} 24$ (polyisobutene), ${ }^{24,25} 24$ (nat. rubber) ${ }^{26}$, and 16 ${ }^{\circ} \mathrm{C} / 1000 \mathrm{kgcm}^{-2}$ [poly(vinyl chloride)], ${ }^{27}$ the pressure dependence of $T_{\mathrm{g}}$ in Penton is rather small.

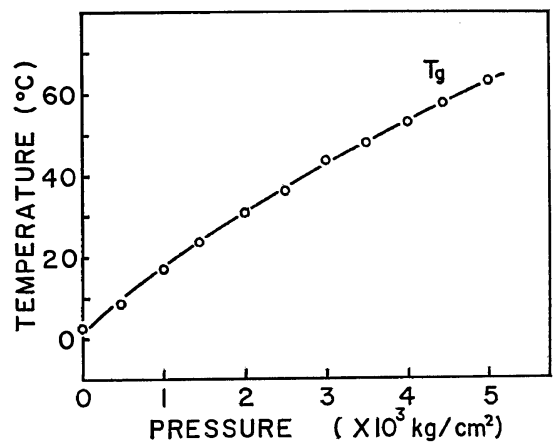

Figure 10. The pressure dependence of the glass transition temperature $T_{\mathrm{g}}$ in Penton.

Pressure Hysteresis on Glass Transition. For the purpose of studying the hysteresis phenomena of glass transition temperature $T_{\mathrm{g}}$ owing to pressure change, the following experimental procedure was undertaken. First, the temperature was raised high enough beyond $T_{\mathrm{g}}$ and then cooled slowly to room temperature under

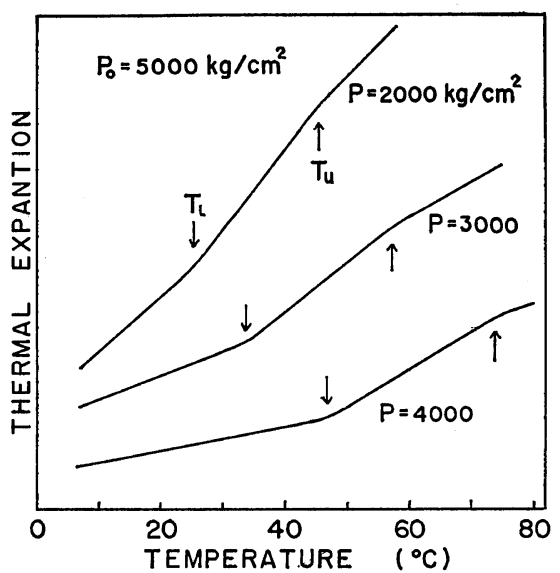

Figure 11. The thermal expansion-temperature curves. Samples were cooled from the rubbery state to the glassy state at pressure $P_{0}=5000 \mathrm{~kg} / \mathrm{cm}^{2}$ and measurements were performed at each reduced pressure indicated in the figure. $T_{\mathrm{u}}$, upper knick point; $T_{1}$, lower knick point.

the constant pressure $\boldsymbol{P}_{0}$. After pressure was reduced quickly to the desired pressure $P$ at room temperature, the thermal expansion was observed at pressure $P$. The obtained curves indicate an anomalous increase and has two knick points in the glass transition region, as shown in Figure 11.

The reason for the appearance of these pressure hysteresis phenomena is explained schematically in Figure 12(a). The dotted line labeled by $\boldsymbol{P}$ represents the volume-temperature curve obtained by the procedure to determine the glass transition temperature at the pressure $P$. When the sample was cooled from the rubbery state to the glassy state at pressure $P_{0}$, the value of the volume of sample locates at point 2. By the reducing of the applied pressure from $P_{0}$ to $P$, the sample expands elastically to point 3 , not up to the point on the dotted line labeled by $\boldsymbol{P}$. As the temperature is raised near the glass transition region, the mobility of the molecular chains in this polymer becomes larger, and the sample volume begins to expand quickly with the quick release of the internal stress contained in this densified sample. ${ }^{16}$ Further, the temperature is raised and mobility becomes large enough to recover from the densified state, and then the sample expands along the dotted volume-temperature curve 


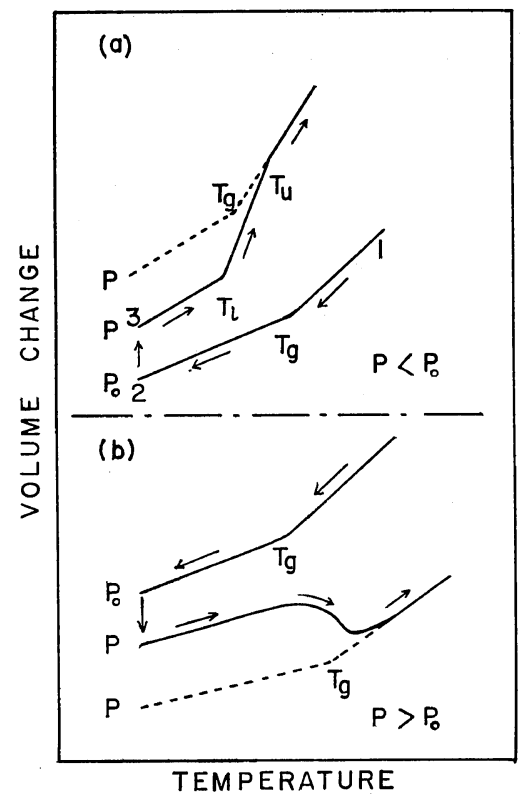

Figure 12. Schematic illustration of behavior of volume change. (a) The case of pressure decrease: The sample was cooled from the rubbery state (point 1) to the glassy state (point 2) at pressure $\boldsymbol{P}_{0}$ and then the applied pressure was reduced to pressure $P$. (b) The case of pressure increase: In the glassy state the pressure was raised from the vitrification pressure $P_{0}$ to the pressure $P$ and then the measurement was performed at the raised pressure $\boldsymbol{P}$.

labeled by $\boldsymbol{P}$. For these reasons, the volumetemperature curve having two knick points may be observed.

In these two knick points, the upper point and lower point are labeled by $T_{\mathrm{u}}$ and $T_{1}$, respectively. Figure 13 shows the $T_{\mathrm{u}}, T_{1}$, and glass transition temperature $T_{\mathrm{g}}$ at the each measuring pressure, and in this case the initial vitrification pressure $\left(\boldsymbol{P}_{0}\right)$ was $5000 \mathrm{~kg} / \mathrm{cm}^{2}$. As the pressure difference $\left(\Delta P=P_{0}-P\right)$ decreases, $T_{1}$ approaches to $T_{\mathrm{g}}$, and $T_{\mathrm{u}}$ becomes indistinguishable. The same experiments were carried out in the cases that the initial vitrification pressure $P_{0}$ was 4500 and $4000 \mathrm{~kg} / \mathrm{cm}^{2}$. In all these cases the temperature difference $(\Delta T=$ $\left.T_{\mathrm{g}}-T_{1}\right)$ decreases near zero with the decreasing pressure difference $\left(\Delta P=P_{0}-P\right)$ and $\Delta T$ has a maximum point in the pressure range where $\Delta P$ is about $2000 \mathrm{~kg} / \mathrm{cm}^{2}$, as shown in Figure 14 .

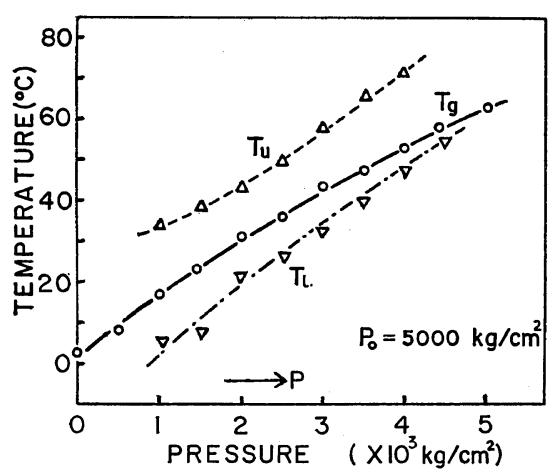

Figure 13. The pressure dependence of $T_{\mathrm{u}}$ and $T_{1}$ : $T_{\mathrm{u}}$ and $T_{1}$ denote the upper and lower knick points in Figure 11, respectively.

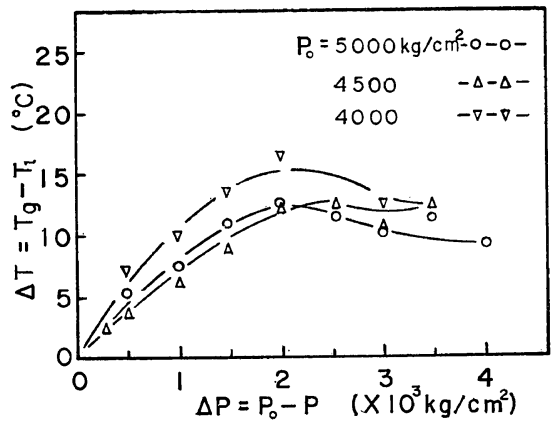

Figure 14. The temperature difference $(\Delta T)$ vs. the pressure difference $(\Delta P)$ curves: $\Delta T=T_{\mathrm{g}}-T_{1}$; $\Delta P=P_{0}-P . T_{\mathrm{g}}$, glass transition temperature at each pressure $P ; T_{1}$, lower knick point in Figure $11 ; P_{0}$, vitrification pressure; $\boldsymbol{P}$, reduced pressure.

But the reason why $\Delta T$ maximum exists has not been studied yet.

On the other hand, when the pressure was raised abruptly to a higher pressure in the glassy state, the obtained volume-temperature curve shows the S-like curve, as shown in Figure 12(b). The dotted line labeled by $\boldsymbol{P}$ represents the volume-temperature curve which is obtained by the procedure to determine the glass transition temperature at the pressure $\boldsymbol{P}$. In this case, the decrease of sample volume by the increased pressure does not occur up to the value on the dotted line. When the sample is heated near the glass transition range, the mobility of the molecular chain increases, and the densification of sample takes place quickly. This may be the reason why the S-like curve is obtained. 
Acknowledgement. This work was supported in part by the Scientific Research Fund of the Ministry of Education.

\section{REFERENCES}

1. B. Wunderlich and T. Arakawa, J. Polym. Sci., Part A, 2, 3697 (1964).

2. J. L. Kardos, A. W. Christiansen, and E. Bear, J. Polym. Sci., Part A-2, 4, 777 (1966).

3. R. Hasegawa, Y. Tanabe, M. Kobayashi, H. Tadokoro, A. Sawaoka, and N. Kawai, $J$. Polym. Sci., Part A-2, 8, 1073 (1970).

4. S. Hirakawa and T. Takemura, Japan. J. Appl. Phys., 8635 (1969).

5. D. J. H. Sandiford, J. Appl. Chem., (London), 8188 (1958).

6. J. L. Kardos, Ph. D. Thesis, Case Institute of Technology, Cleveland, Ohio, 1965.

7. E. Baer and J. L. Kardos, J. Polym. Sci., Part A, 3, 2827 (1965).

8. N. Kawai and Y.Inokuti, Japan. J. Appl. Phys., 7, 989 (1968).

9. G. C. Kennedy, A. Jayarman, and R. C. Newton, Phys. Rev., 126, 1363 (1962).

10. E. Rapoport, J. Chem. Phys., 46, 2891 (1967).

11. T. Yoshida and H. Okamoto, Progr. Theor. Phys., 45, 663 (1971).

12. C.E. Weir, Japan. J. Appl. Phys., 10, 714 (1971).

13. J. M. O'Reilly, J. Polym. Sci., 57, 429 (1962).

14. G. Gee, Polymer, 7, 177 (1966).
15. N. I. Shishkin, Soviet Phys. Solid state, 2, 322 (1960).

16. S. Saito, Rep. Progr. Polym. Phys. Japan, 11, 375 (1968).

17. S. Hirakawa and T. Takemura, Japan. J. Appl. Phys., 7, 814 (1968).

18. E. J. Vanderman, Rev. Sci. Instr., 22, 757 (1951).

19. J. R. Collier and E. Baer, Polymer, 8, 117 (1967).

20. A. Nagai, T. Ishibashi, and M. Takayanagi, Kogyo Kagaku Zasshi (J. Chem. Soc. Japan, Ind. Chem. Sect.), 71, 1033 (1968).

21. Y. Takahashi, H. Tsugaya, and H. Tadokoro, paper presented at the 19th Symposium on Macromolecules, Tokyo, 1970.

22. G. Wasai, T. Saegusa, J. Furukawa, and H. Imai, Kogyo Kagaku Zasshi (J. Chem. Soc. Japan, Ind. Chem. Sect.), 67, 1428 (1964).

23. A. T. Sanzharovskii and G. I. Epifanov, Makhan. Polymerov. Akad. Nauk. Latv. S.S.S.R., 2, 290 (1966).

24. L. E. McKinney and H. V. Belcher, Paper presented at American Physical Society Meeting, Monterey, Calif., March, 1961.

25. A. W. Nolle and J. J. Billings, J. Chem. Phys., 30, 84 (1959).

26. J. E. McKinney, H. V. Belcher, and R. S. Marvin, Trans. Soc. Rheology, 4, 347 (1960).

27. L. A. Igonin, Y. V. Ovchinnikov, and V.A. Kargin, Doklady Akad. Nauk. S.S.S.R., 128 127 (1959). 